\title{
Congenital Heart Diseases associated with Identified Syndromes and Other Extra-Cardiac Congenital Malformations in Children in Lagos
}

\author{
Maladies cardiaques congénitales associées à des syndromes identifiés et extra-Malformations \\ cardiaques congénitales chez les enfants à Lagos
}

\author{
E. N. Ekure ${ }^{* \dagger}$, A. Animashaun ${ }^{\dagger}$ M. Bastos ${ }^{\ddagger}$ V. C. Ezeaka ${ }^{\dagger}$
}

\begin{abstract}
BACKGROUND: Congenital heart diseases are commonly associated with other extra cardiac congenital malformations. OBJECTIVE: To identify congenital heart diseases associated with identified syndromes and other extra cardiac congenital malformations in children in our hospital.

METHODS: A prospective descriptive study done on children with congenital malformations referred to the Lagos University Teaching Hospital, Nigeria (LUTH) for echocardiographic evaluation. A thorough 2D assessment of the chambers, septa, heart vessels and concordance of the atrium and ventricle and the great vessels was made. Echo-cardiographic data obtained included M mode direct measure-ments of dimensions of left atrium, aortic root, right ventricular outflow tract, left ventricle in diastole/systole, wall thicknesses - right ventricular wall, interventricular septum, left ventricular posterior wall. Fractional shortening was derived from $\mathrm{M}$ mode data. Final diagnosis of the congenital heart disease was recorded.

RESULTS: A total of 101 children with congenital malformations had echocardiography studies done as part of their clinical evaluation, $15(14.9 \%)$ were neonates, 53(52.5\%) infants $25(24.8 \%)$ were aged one to five years and $8(7.9 \%)$ were above five years of age. Recognised syndromes were seen in 69(68\%) cases. Down syndrome with 54 children contributed $78.3 \%$ of those with known syndromes. Other identified syndromes and associations were Marfan's, Noonan's, Edwards, Prune Belly, Apert, Ellis-van creveld syndrome and congenital rubella syndrome. Congenital heart diseases were detected in $73(72.3 \%)$ patients while $\mathbf{2 8}(27.7 \%)$ had no heart defect. The commonest identified congenital heart disease was ventricular septal defect affecting $30(29.7 \%)$ patients.

CONCLUSION: Congenital heart diseases are common in children with congenital malformations. Down syndrome was the most common malformation and the congenital heart disease most associated with the congenital malformations was ventricular septal defect. This study emphasizes the need for cardiac assessment of children with congenital malformations. WAJM 2009; 28(1): 323-327.
\end{abstract}

Key words: Congenital malformations, congenital heart diseases, children, echocardiography, abnormalities, anomalies.

\section{RÉSUMÉ}

CONTEXTE: les maladies cardiaques congénitales sont fréquemment associées à d'autres malformations congénitales cardiaques supplémentaires. Objectif: identifier les maladies cardiaques congénitales associées à des syndromes identifiés extra cardiaque et d'autres malformations congénitales chez les enfants dans notre hôpital. MÉTHODES: Une étude descriptive prospective sur les enfants ayant des malformations congénitales visée à l'Hôpital universitaire de Lagos, Nigeria (LUTH) pour echocardiographic évaluation. Une évaluation approfondie 2D des chambres, des cloisons, le cour des navires et de la concordance de l'atrium et le ventricule et les gros vaisseaux a été faite. Echo-cardiographic données inclus $M$ mode mesure directe-ment des dimensions de l'oreillette gauche, la racine aortique, voie d'éjection du ventricule droit, ventricule gauche en diastole / systole, l'épaisseur de paroi - paroi du ventricule droit, septum interventriculaire, la paroi postérieure du ventricule gauche. Fractional raccourcissement ont été tirées des données en mode M. Diagnostic définitif de la maladie cardiaque congénitale ont été enregistrés.

RÉSULTATS: Un total de 101 enfants avec des malformations congénitales a echocardiography études réalisées dans le cadre de leur évaluation clinique, 15 (14,9\%) étaient des nouveau-nés, 53 (52,5\%) des nourrissons $25(24,8 \%)$ étaient âgés de un à cinq ans et $8(7,9 \%)$ étaient au-dessus de l'âge de cinq ans. Reconnu syndromes ont été observés dans 69 (68\%) des cas. Le syndrome de Down, avec 54 enfants a contribué $78,3 \%$ des personnes ayant connu des syndromes. Parmi les autres syndromes de Marfan et les associations ont été, de Noonan, de Edwards, Prune Belly, Apert, Ellis-van Creveld syndrome et le syndrome de rubéole congénitale. Maladies cardiaques congénitales ont été détectées dans 73 (72,3\%) tandis que 28 patients $(27,7 \%)$ n'avaient pas d'anomalie cardiaque. La commune a identifié une maladie cardiaque congénitale du septum ventriculaire a été vice affectant $30(29,7 \%)$ patients.

CONCLUSION: Les maladies cardiaques congénitales sont communs chez les enfants atteints de malformations congénitales. Le syndrome de Down est la plus fréquente de malformation cardiaque congénitale et de la maladie associée à la plupart des malformations congénitales a été ventriculaire septal defect. Cette étude souligne la nécessité d'une évaluation cardiaque des enfants ayant des malformations congénitales. WAJM 2009; 28(1): 323-327.

Mots-clés: malformations congénitales, les maladies cardiaques congénitales, des enfants, l'échocardiographie, les anomalies, les anomalies.

Department of Paediatrics, Department of Nursing Services, Lagos University Teaching Hospital, Lagos, Nigeria.

Correspondence: Ekure, E. N. E-mail: ekaekure@yahoo.com

Abbreviations: ASD, atrioventricular defect; AVCD, atrioventricular canal defect; CoA, co-arctation of the aorta; DORV, double outlet right ventricle; PDA, patent ductus arteriosus; MVP, mitral valve prolapse; PS, pulmonary stenosis; TOF, Tetralogy of fallot; VSD, ventriculo-septal defect. 


\section{INTRODUCTION}

Congenital malformations are anatomical defects and chromosomal abnormalities present at birth. Approximately 2\% of live births have major congenital abnormality. The incidence is increased in pre-term and small for gestational age infants. ${ }^{1}$ Congenital anomalies are among the leading cause of death during the first five years of life in the USA. ${ }^{2}$ Congenital malformations accounts for $8.5 \%$ neonatal deaths in Lagos University Teaching Hospital, Lagos (LUTH). ${ }^{3}$

The externally observed congenital malformations often have other associated internal organ malformations. In the past, due to lack of advanced diagnostic techniques many internal organ malformations were missed. Currently, technological advancement in diagnosis has made it possible to identify the internal organ malformations thus preventing a congenital heart disease to be passed off as pneumonia. This may also have contributed to the seeming increase in congenital malformations in children. A single system can be affected or multiple systems. In a study in Australia, of the 175.9/10,000 cases of congenital malformations which affected all systems, the single most affected system was the heart with $35.9 / 10,000$ cases. ${ }^{4}$

Congenital heart diseases are commonly associated with other extra cardiac congenital malformations and some are particularly seen in certain malformations. This knowledge is very useful in areas where sophisticated diagnostic facilities such as echocardiography machines are absent to make specific diagnosis, guide treatment and hereby reduce mortality. To our knowledge, no such study has been done in our environment ante mortem using echocardiography.

The aim of this study was to document the congenital heart diseases associated with identified syndromes and other extra cardiac congenital malformations in children in Lagos using echocardiography.

\section{SUBJECTSAND METHODS}

Over a period from March 2005 to March 2007 a prospective study was carried out on children with congenital malformations referred to the Lagos University Teaching Hospital, Nigeria (LUTH) for echocardiographic evaluation. Lagos University Teaching Hospital is a 760 bed tertiary institution in the former capital and economic nerve centre of Nigeria. It is a major referral centre in Nigeria with patients coming from both private and public health facilities all over Nigeria especially the western part. The heart of each patient was evaluated using a HP Sonos 2000 echocardiography machine and both $\mathrm{M}$ mode and 2D findings recorded. Transducers with 7.5/ 5.0 or $3.5 \mathrm{MHz}$ were used as determined by age of the patient. The echocardiographic studies were performed by ENE and AA using standard techniques, views, and measurements. ${ }^{5}$ A thorough 2D assessment of the chambers, septa, heart vessels and concordance of the atrium and ventricle and the great vessels was made. Echocardiographic data obtained included $\mathrm{M}$ mode direct measurements of dimensions of left atrium, aortic root, right ventricular outflow tract, left ventricle in diastole/ systole, wall thicknesses - right ventricular wall, interventricular septum, left ventricular posterior wall. Fractional shortening was derived from $\mathrm{M}$ mode data.

All children without obvious external congenital malformations were excluded. Congenital heart disease was defined as a structural abnormality of the heart such as defects in cardiac septation, abnormalities of ventriculo-arterial connections, rudimentary or absent chambers, abnormalities of ventricular inflow and outflow, and abnormal vascular connections and structures. Final diagnosis of the congenital heart disease was recorded. Biographic data of patient and parents, clinical diagnosis of the child were then obtained using a structured questionnaire. Consent was obtained prior to recruitment into study.

Data was analysed using SPSS 11.0 software. Frequency distribution tables were generated for the congenital malformations and associated congenital heart diseases.

\section{RESULTS}

Demographic Data

A total of 101 children with congenital malformations had echocardiography studies done as part of their clinical evaluation. Their ages ranged from birth to 14 years. Among the 101 children, $15(14.9 \%)$ were neonates, $53(52.5 \%)$ infants, 25(24.8\%) were aged 1 to 5 years and $8(7.9 \%)$ were above 5 years. (Table 1). Fifty-four $(53.5 \%)$ of the 101 children with congenital malformations were males while $47(46.5 \%)$ were females giving a male: female ratio of 1.1:1. In the different age group categories, the sexes were almost equally shared except for the neonates where the males made up $66.7 \%$ of the cases.

The age of the fathers of the children ranged from 26 years to 65 years with a mean of 39.6(7.1) years. The age of the mothers of the children ranged from 23years to 50years with a mean of 34.1(5.9) years. There was no case of consanguinity in all cases studied.

Table 1: Distribution of Patients by Sex and Age

\begin{tabular}{lr}
\hline Characteristic & Number(\%) \\
\hline Age Group & \\
$\quad$ Neonates & $15(14.9)$ \\
Infants & $53(52.5)$ \\
1-5years & $25(24.8)$ \\
>5years & $8(7.9)$ \\
Sex Distribution & \\
Male & $54(53.5)$ \\
Female & $47(46.5)$ \\
\hline
\end{tabular}

\section{Congenital Malformations}

Recognised syndromes were seen in 69(68\%) cases. Down's syndrome with 54 children contributed $77.1 \%$ of those with known syndromes. Other identified syndromes and associations were Marfan's, Noonan's, Edwards, Prune Belly, Apert, Ellis-van creveld syndrome and congenital rubella syndrome. (Table 2).

There were 22 musculoskeletal defects, 20 of which were defects of the palate and or lip, choanal atresia ${ }^{1}$ and one case of syndactyly and right leg below knee amputation. There were also central nervous system defects seven(6\%) and GIT defects one $(1 \%)$.

Associated Congenital Heart Diseases

Congenital heart diseases were detected in 73(72.3\%) patients while 
This high rate may be a reflection of the study population as some of the patients may have been referred for evaluation because of symptoms of heart disease and not as a routine check because of the congenital abnormality. The congenital malformations can be lethal or non lethal. The lethal ones may actually be so classed because of the associated complex heart abnormality.

Identified syndromes were seen in $70 \%$ of the patients with $77 \%$ of them being cases of Down's Syndrome. The next common syndromes were Marfan, Noonan's and congenital rubella syndromes with three cases each. It is known that there are associations of congenital heart diseases with certain congenital anomalies. The findings of this study are in keeping with the association between Down syndrome and congenital heart defects. Of the 54 cases with Down syndrome, only $7(13 \%)$ had no congenital heart disease leaving $87 \%$ of the cases with congenital heart diseases.

Among patients with Down syndrome, it is reported that about $50 \%$ of them have congenital heart diseases. ${ }^{6}$ The high rate in this study again may be due to the select group studied. Literature varies as to which congenital heart disease is commonest among the patients with Down syndrome. Whereas some report atrioventricular canal defect as the commonest $^{7-10}$ others report ventricular septal defect. ${ }^{11-13}$ In this report, ventricular septal defects and atrioventricular canal defects were the two commonest cases seen with 21 and 20 cases respectively in patients with Down syndrome. This clearly shows that the two commonest congenital heart diseases associated with Down syndrome remain Ventricular septal defect and atrioventricular canal defect.

Most of the other syndromes also had expected heart abnormalities. The three cases with Marfan's syndrome had mitral valve prolapse and aortic root enlargement while two of the three cases with congenital rubella that had heart defects had Patent Ductus Arteriosus ${ }^{14}$. There were two cases of Edward's syndrome, a trisomy chromosomal abnormality like Down's syndrome. While $50 \%$ of cases of Down's syndrome are expected to have congenital heart diseases, 90\% is expected in Edward's syndrome especially ventricular septal defect. The two cases had double outlet right ventricle and a combination of atrial and ventricular septal defects respectively.

Ellis-van Creveld syndrome (chondroectodermal dysplasia) is reported to be associated with single atrium. The only case in this report had tetralogy of Fallot. Turner's syndrome was associated with coarctation of the aorta as expected. Apert's syndrome is reported to be occasionally associated with congenital heart defects. The case with Apert's syndrome in the study had no congenital heart disease. Prune Belly a urinary tract anomaly usually has no association with heart defects and the only case in the report had no congenital heart disease.

Lesions of the musculoskeletal system followed Down's syndrome with 22 cases. Twenty of them were defects of the palate and or lip. Whereas $100 \%$ of the cases with cleft lip had no cardiac defect, $75 \%$ of those with cleft palate had cardiac defects and $60 \%$ of those with both cleft lip and palate had no cardiac defect. It therefore appears that a patient with cleft palate is more likely to have an associated heart defect than a patient with cleft lip. More subjects with cleft lesions need to be studied to confirm this observation.

Congenital anomalies are a major cause of morbidity and mortality with congenital heart diseases contributing to this. Identification and correction of any identified lesion will reduce the mortality burden from this cause. There is need for an early and proper cardiovascular evaluation of all children with congenital anomalies. Assessment of all newborns with Down's syndrome with an echocardiogram is the standard recommendation. ${ }^{15-16}$ This requires facilities and trained personnel for cardiac evaluation and surgery to cater for this group of patients in our sub region.

There has been a dramatic improvement in the prognosis of children with congenital heart diseases in regions were the technology and personnel to carry out cardiac interventions are available. It is reported that in $198660 \%$ of deaths from congenital heart disease occurred in the first year of life, whereas in the 1990s the majority of deaths occurred in adults over the age of 20 years. ${ }^{17}$ It is predicted that $78 \%$ of the babies born with congenital heart disease today will survive into adulthood. ${ }^{18} \mathrm{~A}$ national policy for Paediatric heart care and International collaboration to build effective and sustainable cardiac surgery programmes are required.

This result confirms the well known association of some congenital abnormalities such as Down's, Edwards, Turner's, Marfan's and rubella syndromes in our sub Saharan African environment. It demonstrates a high association of congenital heart diseases with extra cardiac congenital malformations and Down Syndrome to be the most commonly seen congenital anomaly with an $87 \%$ rate of associated congenital heart disease. This knowledge serves as a guide for the region in evaluating children with congenital malformations. It shows that the reported associations of some congenital malformations with congenital heart defects in the developed countries are similar to what pertains in the tropics. Hence management of the patient can be guided by these associations when sophisticated equipment for thorough diagnosis is absent.

\section{REFERENCES}

1. Roizen NJ, Patterson D. Down's syndrome. Lancet 2003; 361: 12811289.

2. Behrman RE, Kliegman RM, Jenson HB. (Editors). Overview of Paediatrics: In Nelson Textbook of Pediatrics, Sixteenth edition. Philadelphia, Pa: WB Saunders Co; 1996: 1-3.

3. Ekure EN, Ezeaka VC, Iroha EO, EgriOkwaji MTC. Neonatal Mortality of Inborns in the Neonatal Unit of a Tertiary Centre in Lagos, Nigeria. Nig Qt J Hosp Med 2005; 15: 55-58.

4. UNSW National Perinatal Statistics Unit. AIHW. Congenital Malformations, Australia 1997; 4.www.aihw.gov.au/ npsu/cm97.pdf.

5. Henry WL, DeMaria A, Gramiak R, King DL, Kisslo JA, Popp RL, et al. Report of the American Society of Echocardiography Committee on Nomenclature and standards in Twodimensional echocardiography. Circulation 1980; 62: 212.

6. Freeman SB, Taft LF, Dooley KJ. Population-based study of congenital 
heart defects in Down Syndrome. Am J Med Genet 1998; 80: 213-217.

7. Tandon R, Edwards JE. Cardiac malformations associated with Down's syndrome. Circulation 1973; 47: 416.

8. Greenwood RD, Rosenthal A, Parisi L, Fyler DC, Nadas AS. Extracardiac Abnormalities in Infants With Congenital Heart Disease. Pediatrics 1975; 55: 485-492.

9. Geggel RL, O'Brien JE, Feingold M. Development of valve dysfunction in adolescents and young adults with Down syndrome and no known congenital heart disease. J Pediatr 1993; 122: 821-23.

10. Jaiyesimi FO, Ruberu DK. Noncardiac Defects in Children with Congenital
Heart Disease. Ann Saudi Med 1994; 14: 183-186.

11. Abbag FI. Congenital heart diseases and other major anomalies in patients with Down Syndrome. Saudi Med J. 2006; 2: 219-22.

12. Lo NS, Leung PM, Lau KC, Yeung CY. Congenital cardiovascular malformations in Chinese children with Down's Syndrome. Chin Med J 1989; 102: 3826.

13. Hoe TS, Chan KC, Boo NY. Cardiovascular malformations in Malaysian Neonates with Down's Syndrome. Singapore Med J. 1990; 31: 474-6.

14. Park MK. History Taking in Pediatric Cardiology for Practitioners. Mosby,
Elsevier Science, 2002: 3-9.

15. American Academy of Pediatrics Committee on Genetics. Health supervision for children with Down Syndrome. Pediatrics 2001; 107: 442-49.

16. Cohen WI. Health Care Guidelines for Individuals with Down Syndrome: 1999 revision. Down Syndrome Quar 1999; 4: $1-15$.

17. Office for National Statistics (2003) Mortality statistics: childhood, infant and perinatal (Series DH3 No. 34). HMSO; London. www.heartstats.org

18. Perloff JK, Warnes CA. Challenges posed by adults with repaired congenital heart disease. Circulation 2001; 103: 2637-43. 